\title{
Effect of Socio-demographic Characteristics on Healthcare Seeking Behaviour among Users of Primary Health Care Facility in Ado-Odo Ota Local Government Area, Ogun State, Nigeria
}

\author{
Article by Musah K.Toyin \\ Department of Community Health Science, College of Pure and Applied Sciences, \\ Kwara State University, Malete, Nigeria. \\ Email:musahtoyin1@gmail.com; khadijat.musah@kwasu.edu.ng
}

\begin{abstract}
Introduction: Healthcare seeking behaviour has been defined as any set of actions undertaken by an individual who perceives a health problem or an illness for the purpose of finding an appropriate remedy ${ }^{1}$. This is based on an Explanatory model which has a coherent picture of specific cultural features and these features in turn predispose an individual to certain health behaviour. Against the backdrop of the need for understanding the effects of socio-demographiccharacteristics on healthcare seeking behaviour of individuals from sociological perspectives, this study assessed some of those factors among users of primary health care facility (PHC)in Ado-Odo Ota local government (LGA), Ogun State, Nigeria.

Methods: Descriptive cross sectional study among 300 selected users of PHC that are resident of Ado-Odo Ota using multistage sampling method. Data was analyzed using the SPSS software version 21.0. Three hundred (male-97, female 203) users of PHC were sampled through multistage sampling technique in these wards. Instrument used for data collection was a self-developed, validated questionnaire with reliability of 0.72 using Chrombach alpha coefficient. Multiple regression, Analysis of Variance and Independent Ttest were used to test the hypotheses at 0.05 level of significance.

Results: Using the framework from the 'four As' theories and concepts; findings based on the survey revealed that household headship, educational level and income predicted increase in service utilization at PHC in Ado-Odo Ota LGA $\left(R=.252 ; R^{2}=.064 ;\right.$ Adj. $\left.R^{2}=.054\right) ;(F$ calculated $_{(3,299)}=6.715>f$-table $\left.=3.86 ; p<.05\right)$. Statistical significance also existed in service utilization between male and female in the study area.

Conclusion: Based on the study outcome, it was recommended among others that there is need for continuous community mobilization by healthcare providers especially the Public/Community health Nurses and Community extension workers to enhance active community involvement and continuous increase in service utilization.
\end{abstract}

Keywords: Healthcare seeking, PHC Users, Ogun State, Nigeria.

\section{Introduction}

Health care seeking behaviour has been defined as any set of actions undertaken by an individual who perceives a health problem or an illness for the purpose of finding an appropriate remedy ${ }^{1}$. This is based on an Explanatory model which has a coherent picture of specific cultural features. These features in turn predispose an individual to certain health behaviour. The Explanatory model of a particular illness for example consists of signs and symptoms by which the illness is recognised prior to diagnosis. The presumed cause of the illness and prognosis can then be established $^{2}$. These are in turn interpreted by individuals or significant others who proceed to address it appropriately through standard diagnostic procedure ${ }^{2,3}$. Health seeking behaviour is preceded by a decision making process that is basically governed by individual and/or household behaviour, community norms and expectations as well as provider-related characteristics. For this reason the nature of care seeking is not homogenous depending on cognitive and non-cognitive factors which call for a contextual analysis of care seeking behaviour ${ }^{3}$. 
Typically, a health care seeking pattern involves recognition of symptoms, perceived nature of illness, followed initially by appropriate home care and monitoring. This may necessitate seeking care at the health facility, medication compliance and finding cure, either partially or totally. However, there may be treatment failure and this may require a return to the health facility or finding an alternative care provider ${ }^{3}$. Thus, client-based factors, provider-based factors, caretaker perceptions; social and demographic factors, cost, social networks and biological signs and symptoms work in consonance to produce a pattern of health seeking behaviour ${ }^{4}$. From the foregoing, it is possible that an integrated behavioural pattern emerges from the attention given to the illness and a multiplicity of treatment protocol. In addition to components of the Explanatory models, there are noncognitive factors such as availability and cost of health services that are key to the decision making process ${ }^{5,6}$. The Determinant models of health seeking behaviour focus mainly on demographic factors. For example level of education, occupation and income of the head of household are considered as critical in developing countries ${ }^{4}$. Cost of care and nearness of facilities to users of services also play important roles in influencing the observed health-seeking behaviour.

\section{The Problem}

The transition from illness to health care seeking behaviour can be multidimensional particularly if the illness is not life threatening. For instance, cost of medical care is a real concern to poor people in this part of the world. Poverty and vulnerability of means of livelihood therefore influence the health status and vice versa. In addition, there must be compliance with the provision of primary health care services as determined by the interactions of all people within the health care systems $^{7}$. It is important to add that this is socio-cultural dimension of health seeking behaviour. There are concerns that user fees may restrict access to health services or lead to change in healthcare seeking behaviour with its detrimental effect on the poor. It stands to reason that whatever becomes unaffordable may be inaccessible. Many other reasons have also been advanced for household's and individual's care seeking behaviour for the treatment of different ailments. These include knowledge and duration of sickness, attitudinal pre-disposition to illness behaviour, the anticipated cost of treatment, and patient's judgement of the intensity of sickness, accessibility to health facilities, socio-cultural belief, level of endemicity in the population and subtle demographic characteristics ${ }^{8}$. To build a responsive and sustainable health system, there is a strong need to understand the health seeking behaviour on the demand side. This is the only way to expect improved health outcomes especially from the grass root where most of the beneficiaries reside. It is against this backdrop that this study aims at gaining insight on the effects of socio-demographic characteristics on healthcare seeking behaviour among among users of Primary Health Care facilities in Ado-odo Ota local government area of Ogun State, Nigeria. Hence, it was hypothesised that socio-demographic characteristics will not significantly reduce or increase service utilization at Primary Health Care facilities in Ado-odo Ota local government area of Ogun State, Nigeria and that there will be no significant difference in the male and female perception on service utilization in PHC.

\section{Methods}

\section{Description of study area}

Ado-Odo/Ota Local Government, the most populous, industrialized Local Government in the State and second most industrialized in the country ${ }^{9}$. It came into existence in May 19, 1989 following the merging of Ota, part of the defunct Ifo/Ota Local Government with Ado-Odo/lgbesa Areas of the Yewa South Local Government. The Local Government is the second largest in Ogun State and it's 
headquarter is at $\mathrm{Ota}^{9}$. It is located within the tropical zone lying between $60470 \mathrm{~N}$ of the equator and $2033^{\circ} \mathrm{E}$ and $3018^{\circ} \mathrm{E}$ of the Greenwich Meridian, covering a land area of 1,263 square kilometres, it has a terrain of 1,010.4 square kilometres plain land about 252.6 square kilometres bad terrain comprising of $16 \%$ riverine and $4 \%$ hilly regions ${ }^{9}$. The Local Government covers an area of 1460 square kilometres and share boundaries with Lagos State in the South, Yewa South and Ifo Local Government in the West and Ipokia Local Government in the North East ${ }^{9,10}$. AdoOdo/Ota Local Government has an estimated population of 527,242 (Male 261,523 and Female 265,719) (2006 Census) with about Four hundred and fifty (450) towns, villages and settlements. The people of the Local Government is dominated mainly by the Aworis (the original owner of the land), Eguns and Yewas (Egbados) and other ethnics groups like Egba settlers in Iju, Atan, Ijoko and Sango - Ota. Expatriates and other ethnics group have equally found the entity a congenial place for settlement. Apart from Ota, Ado-Odo, Igbesa and Agbara, other major towns are Iju-Ota, Owode, Ilogbo, Iyesi, Ijoko, Ajibode, Abule Iroko and host of others ${ }^{9,10}$. To a certain extent, the people are merchandise and industrially inclined, occupationally.

From available data, the Local Government is one of the educationally inclined entities in the Federation sponsoring one hundred and thirteen (113) public primary schools. There are eighteen (18) Public Secondary Schools supported by a good number of Private Nursery Primary and approved Private Secondary Schools in the area $^{9,10}$.

Politically, the Local Government has sixteen (16) constitutional wards with a Councillor representing each ward at the Local Government headquarters in Ota. These wards are: Ota I, Ota II, Ota III, Sango, Ijoko, Atan, Iju, Ilogbo, Ado-Odo I, Ado-Odo II. Others are Ere, Alapoti, ketu Adie-Owe, Agbara 1. Agbara II and Igbesa $^{9,10}$. Health services are available in a number of government owned tertiary, secondary and primary facilities alongside private and religious health facilities. Based on available data, there are 42 Health Centers and Health Post in the Local Government $^{9,10}$. 
South American Journal of Public Health

Volume 4, Issue 1, 2016

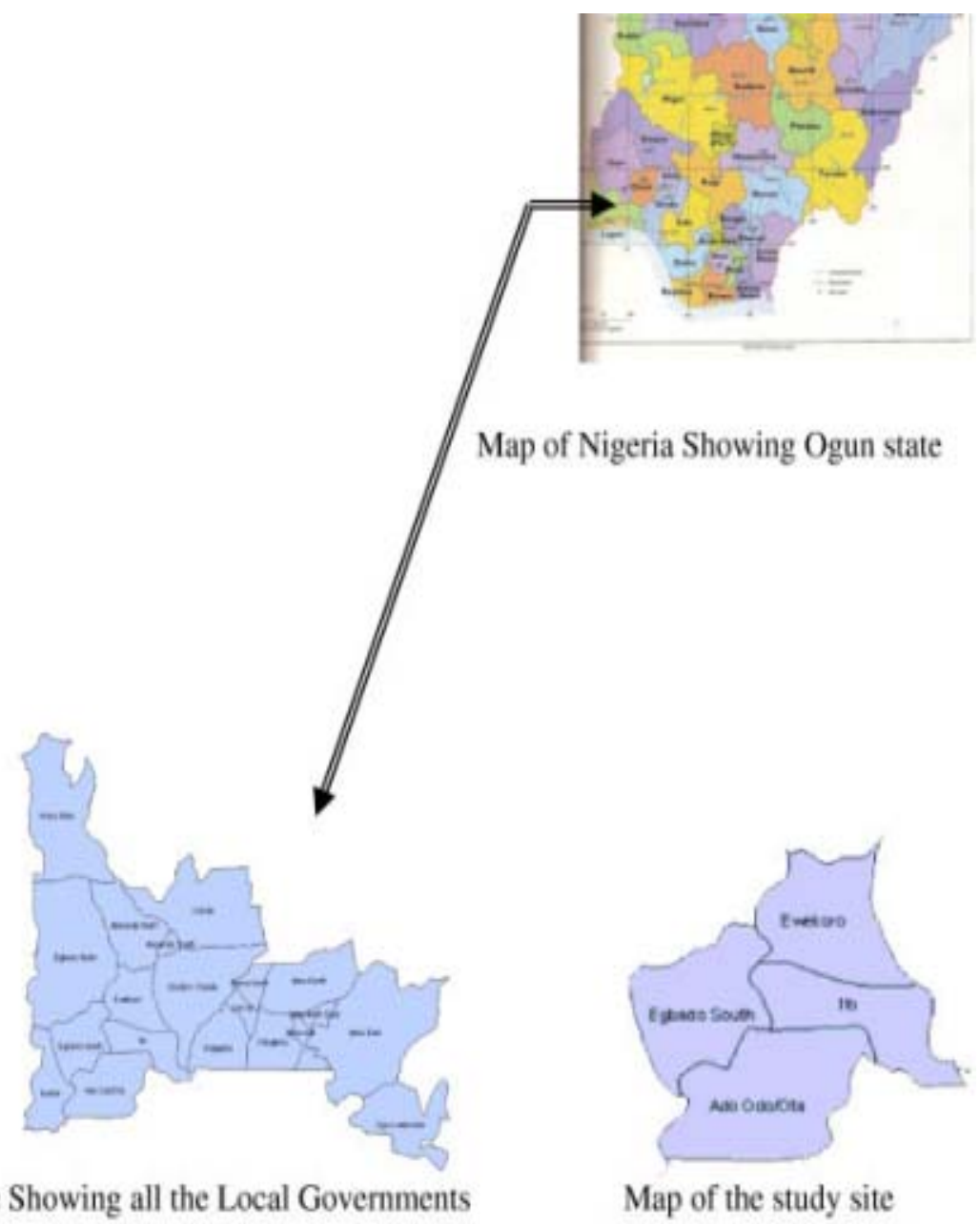

Figure 1. Map of Ogun State showing the study area Source: imgbuddy.com

\section{Study design}

A descriptive cross-sectional survey was adopted for the study which was conducted between October to December, 2015 using highly structured pre-tested self-administered questionnaire among three hundred respondents (male-97, female203). Multi-stage sampling method was used and involved doing simple random sampling in 3 stages to select the respondents in the study area.

\section{Sampling and sampling procedure}

The geo-political wards in Ado-Odo Ota LGA summing up to sixteen was pooled together; eight wards were selected from there using simple random sampling technique by balloting without replacements. Three settlements were selected from each selected ward using the simple random sampling technique by balloting. Two streets were then selected from each selected settlements using the simple random sampling technique by balloting. Cluster in cluster sampling method was used to pick the houses that were sampled in each selected settlement. The first house was picked using the spin the bottle method. The households that were sampled were selected from the previously selected houses using simple random sampling technique by balloting. This is further illustrated with chart below: 


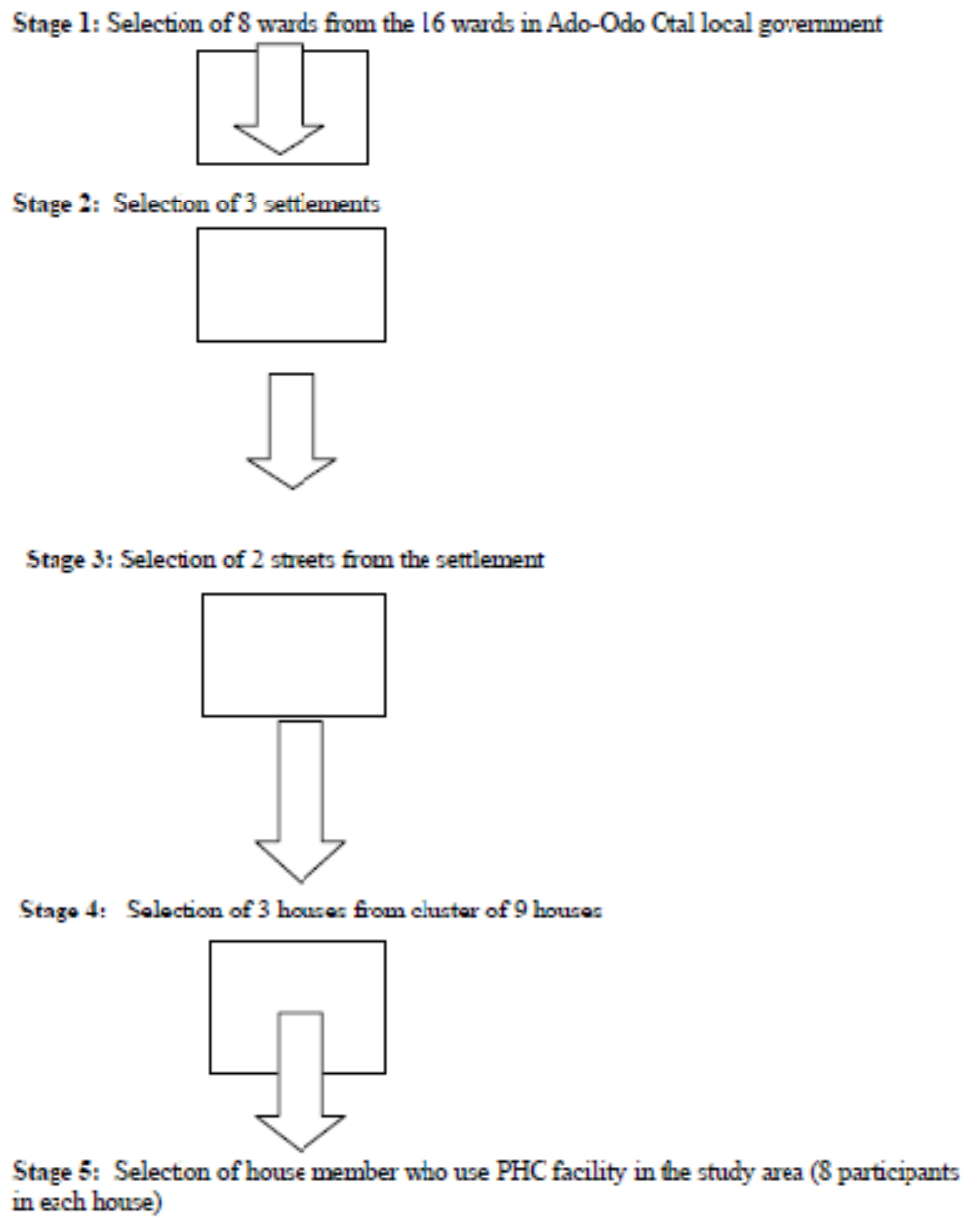

Figure 2. Flow chart for sampling technique (Stage 1- 5)

\section{Instrument}

For the purpose of data collection for analysis, a self-design instrument titled healthcare seeking behaviour questionnaire (HCSBQ) was used. The questionnaire was in two sections. Section A was on demographic characteristics of respondents while section B focused on items that enquire about factors influencing healthcare seeking behaviour in PHC. The response categories in these sections were in the form of yes and no answer. Test-retest method was used to ascertain the consistency and reliability of the instrument. Crombach Alpha was used to find the reliability coefficient of this instrument and was found to be 0.72 .

\section{Inclusion Criteria}

The population for sampling consist of adults above 18 years who have been residing in the study area for the past six months and were willing to participate in the study.

\section{Exclusion Criteria}

People who just came into the community, visitors and people who were not willing to participate in the study were excluded.

\section{Ethical issues and consent}

Ethical clearance was obtained from the Supervisor and the Health Educator in charge of PHC facility in Ado-Odo Ota local government for approval to conduct the study. Consent forms were given to participants to sign prior to administration of questionnaires. All information was treated confidentially. 
South American Journal of Public Health

Volume 4, Issue 1, 2016

\section{Results}

\section{Hypotheses testing}

Socio-demographic characteristics will not significantly reduce or increase service utilization at PHC in Ado-Odo Ota Local Government, Ogun State. Multiple regression and Analysis of Variance were used to statistically look at the effect of demographic characteristics such as household headship, monthly income and level of education on service utilization, whereas, independent t-test was used to analyse the influence of gender on service utilization in PHC.

Table 1(a). Model summary of the regression analysis of the influence of household headship, educational level and income on service utilization at PHC

\section{Model Summary}

\begin{tabular}{|l|l|l|l|l|}
\hline Model & $\mathrm{R}$ & R Square & $\begin{array}{l}\text { Adjusted } \\
\text { Square }\end{array}$ & $\begin{array}{l}\text { Std. Error of } \\
\text { the Estimate }\end{array}$ \\
\hline 1 & $.252^{\mathrm{a}}$ & .064 & .054 & 3.82070 \\
\hline
\end{tabular}

a. Predictors: (Constant), Household headship, Level of Education, Monthly Income

Source: Researcher's field survey, 2015.

The results in Table 1(a) indicate that when household headship, educational level and income entered into the regression model it predicted increase in service utilization at PHC (R $=.252 ; \mathrm{R}^{2}=.064$; Adj. $\left.\mathrm{R}^{2}=.054\right)$. This shows that, household headship, educational level and income combined to predict increase service utilization at PHC. Also, the demographic factors as the predictor variable accounted for $5.4 \%$ of the variance observed in the increase service utilization.

Table 1 (b). ANOVA ${ }^{\text {a }}$

\begin{tabular}{|l|l|l|l|l|l|}
\hline Model & $\begin{array}{l}\text { Sum } \\
\text { Squares }\end{array}$ & Df & Mean Square & F & Sig. \\
\hline Regression & 294.070 & 3 & 98.023 & 6.715 & $.000^{\mathrm{b}}$ \\
Residual & 4320.927 & 296 & 14.598 & & \\
Total & 4614.997 & 299 & & & \\
\hline
\end{tabular}

a. Dependent Variable: Service utilization

b. Predictors: (Constant), Household headship, Level of Education, Monthly Income

Source: Researcher's field survey, 2015.

The results in Table 1(b) tests whether the overall regression model is a good fit for the data. The result shows that household headship, educational level and income statistically and significantly predicted increase service utilization $\left(\mathrm{F}_{\text {calculated }}(3,299)=6.715>\right.$ f-table $=3.86$; $\mathrm{p}<.05$ ). This implies that regression model is a good fit for the data.

Table 1(c). Coefficients ${ }^{\mathrm{a}}$

\begin{tabular}{|l|l|l|l|l|l|}
\hline Model & \multicolumn{2}{|l|}{$\begin{array}{l}\text { Unstandardized } \\
\text { Coefficients }\end{array}$} & $\begin{array}{l}\text { Standardized } \\
\text { Coefficients }\end{array}$ & T \\
\cline { 1 - 5 } & B & $\begin{array}{l}\text { Std. } \\
\text { Error }\end{array}$ & Beta & \\
\hline
\end{tabular}




\begin{tabular}{|l|l|l|l|l|l|}
\hline (Constant) & 45.662 & 1.726 & & 26.454 & .000 \\
Monthly Income & -.041 & .142 & -.018 & -.290 & .772 \\
Level of Education & .302 & .364 & .049 & .830 & .407 \\
Household headship & 1.163 & .297 & .251 & 3.920 & .000 \\
\hline
\end{tabular}

a. Dependent Variable: Service utilization

Source: Researcher's field survey, 2015.

Table 1(c) above revealed the relative contribution of household headship, educational level and income to the prediction of increase in service utilization. The results showed that household headship is the most potent factor among the demographic factors predicting increase in service utilization (beta value $=.251$; $\mathrm{T}$ - value $=3.920>$ T-table $=1.96 ; \mathrm{p}<.05$ ).

Going through all the three tables (a, b, and c); it could therefore be said that the null hypothesis which stated that socio-demographic characteristics-household headship, educational level and income will not significantly reduce or increase service utilization at PHC in Ado-Odo Ota Local Government, Ogun State is rejected. This implies that household headship, educational level and income significantly increase service utilization at PHC in the study area.

Table 2. Independent t-test analysis of differences in service utilization in PHC between male and

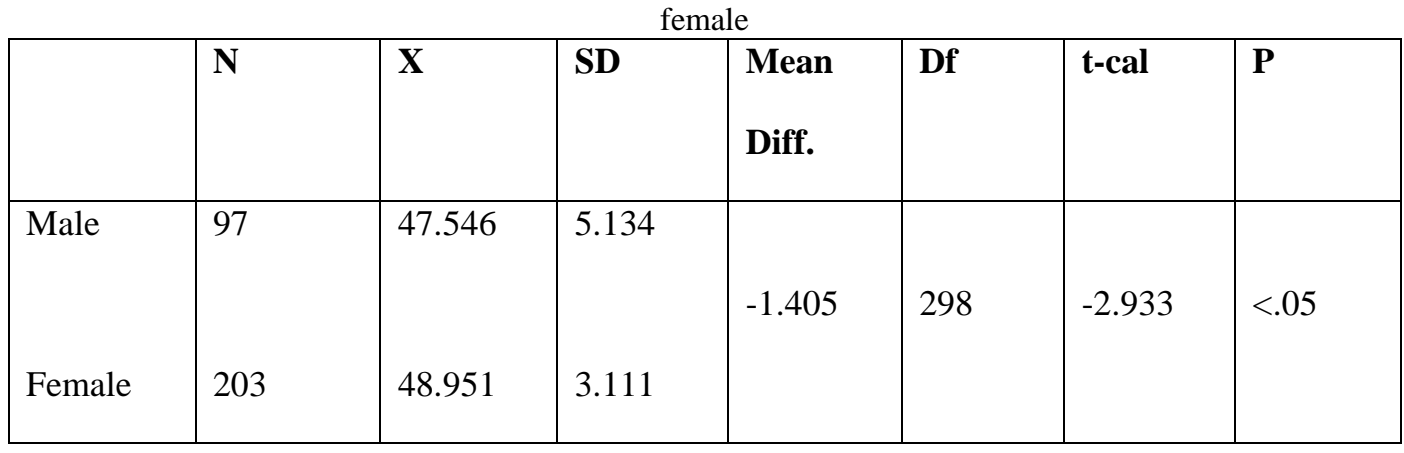

Source: Researcher's field survey, 2015.

Results from the above table indicates a significant difference in the male and female perception of service utilization in PHC (Mean diff. $=1.405 ; \mathrm{t}=-2.933$; $\mathrm{P}<.05$ ). The null hypothesis was rejected. Therefore, male and female differs in the perception of service utilization in PHC.

\section{Discussion}

Many studies identify socio-demographic characteristics and found economic status as the most significant predictor of service use ${ }^{11,12}$ and how income affects the level to which health care facilities are sought and used. According to Buor ${ }^{13}$ the ability to pay determines the use of health services. A lack of finances seriously affects health care seeking ${ }^{14}$, although the willingness to pay for services may be there ${ }^{15}$, the means to do so, may not. Not surprisingly low income has been found to be a barrier to health care seeking and can create an overwhelming financial burden for some ${ }^{16}$. In this present study, majority of the respondents earned above \#25,000 per month and this has helped in increasing their service utilization. This result also corroborates Onwujekwe ${ }^{17}$ study when he assessed the effects of socioeconomic inequities in healthcare seeking in the treatment of common communicable endemic diseases, with an emphasis on the use of primary health care (PHC) centres in four local government areas in Southeast Nigeria found that regular income increased service utilization. 
Household headship and level of education were also found to increase service utilization in Ado-Odo Ota local government. This can be attributed to the fact that majority of the respondents were educated (see table 4.2.5). The outcome of this study concurred with the past studies from literature. ${ }^{12,18,19}$

Significant difference also occurs in the male and female perception of service utilization in PHC (Mean diff. $=1.405 ; \mathrm{t}=-2.933 ; \mathrm{P}<.05$ ). The null hypothesis was rejected. Therefore, male and female differs in the perception of service utilization in PHC.

The above findings might be due to the fact that female use PHC services than their male counterpart. They attend clinics for antenatal, postnatal, infant welfare and for family planning commodities. Several studies have also revealed this variance. ${ }^{12,18,19,20}$

\section{Conclusion and recommendations}

The findings support the view from elsewhere that socio-demographic characteristics remains a strong catalyst for care seeking in developing countries including Nigeria. Based on the study outcome, it is recommended that there is need for continuous community mobilization by healthcare providers especially the Public/Community Health Nurses and Community Health Extension Workers (CHEWs) to enhance active Community involvement and continuous increase in service utilization. The Nigeria Government should also provide more gainful employment to its citizenry as this will empower Users of PHC facility the more.

\section{References}

[1]. Ado-Odo/Ota Local Government. Ogun State Ministry of Local Govt. and Chieftancy Affairs. www.ikimap.com Retrieved 3 October,2015.

[2]. Akande T.M.,Owoyemi J.O. Health Seeking Behaviour in Ayingba, North-Central Nigeria. Research Journal of Medical Sciences 2(4):185-189 2009.

[3]. Buor, D. Analysing the primacy of distance in the utilization of health services in the Ahafo-Ano South district, Ghana. International Journal of Health Planning \& Management., 18(4), 293-311. 2003.

[4]. Caldwell JC, Caldwell P. What have we learnt about the cultural, social and behavioural determinants of health? From Selected Readings to the first Health Transition Workshop. Health Transit Rev 1991; 1: 3-19.

[5]. Craig P, Forbes J. Social position and health: are old and new occupational classifications interchangeable? J Biosoc Sci 2005; 37:89-106.

[6]. Foster, G.M. and Anderson, B.G. Medical Anthropology. John Wiley and sons Inc. USA. Kleinman, A. Patients and Healers in the context of culture. Berkeley: University of California press, 1980.

[7]. Foreit, J., \& Foreit, K. The reliability and validity of willingness to pay surveys for reproductive health pricing decisions in developing countries. Health Policy, 63(1), 37-47. 2003.

[8]. Gotsadze, G., Bennet, S., Ranson, K., \& Gzirishvili, D. Health care-seeking behaviour and out-of-pocket payments in Tbilisi, Georgia. Health Policy and Planning, 20(4), 232-242. 2005.

[9]. Hausmann Muela, S. Community understanding the malaria, and treatment seeking behaviour in a holeendemic area of south-eastern Tanzania. Ph.D Thesis Swiss Tropical Institute, University of Basel, Switzerland. 2012.

[10]. HERFON; Proceedings of National Health Conference. Theme: 'Primary Health Carein Nigeria: Thirty years after Alma Ata. Abuja, Nigeria.

[11]. Institute of Development Studies. Mobilizing social science research to improve health. IDS Policy Briefing. Issue 23. Sussex. 2005.

[12]. MacKian S. A review of health seeking behaviour: problems and prospects. Internal concept paper. Health Systems Development Programme, London School of Hygiene and Tropical Medicine. London. 2001.

[13]. Musah K.T \& Kayode O.O. Preliminary Assessment of Healthcare Seeking Behaviour Among Users of Primary Health Care Facilities in Ilorin Metropolis, Kwara State, Nigeria. IOSR Journal of Nursing and Health Science (IOSR-JNHS) Volume 3, Issue 4 Ver. I (Jul-Aug. 2014), PP 31-35 www.iosrjournals.org

[14]. Musah K.T., Okeya E.O., Kayode O.O., Abuh A., \& Obinna R. Effects of Socio-demographic Characteristics on Health Care Seeking Behaviour among Residents of Ilaje Local Government Area, Ondo State, 


\section{South American Journal of Public Health \\ Volume 4, Issue 1, 2016}

Nigeria. A paper presented at the International Conference on Health \& Wellbeing; Bristol, United Kingdom. June 22-26, 2013.

[15]. Nyamongo, I. K. Health care seeking behaviour of malaria patients in a Nigerian rural community. Social Science \& Medicine, 54(3), 377-386. 2002.

[16]. Onwujekwe O. Inequities in healthcare seeking in the treatment of communicable endemic diseases in Southeast Nigeria. Soc Sci Med. 2005 Jul;61(2):455-63.

[17]. Post Offices- with map of LGA . NIPOST. Archived from the original on 7 October 2009. www.ikimap.com Retrieved 3 October,2015.

[18]. Ryan, G.W. What do sequential behaviour patterns suggest about medical decision making process? Modelling home case management of acute illness in a rural Cameroonian village. Social Sci. Med. 2005; 46:209225.

[19]. World Health Organization. Jakarta Declaration on Leading Health Promotion into the 21st Century. The Fourth International Conference on Health Promotion: New Players for a New Era- Leading Health Promotion into the 21st Century. Jakarta. 1997.

[20]. World Health Organization. Mexico Ministerial Statement for the Promotion of Health. The Fifth Global Conference on Health Promotion. Health Promotion: Bridging the Equity Gap. Mexico City. 2000. 